\title{
PROGRAMA ALFA E BETO DE ALFABETIZAÇÃO: CONCEITOS DE LINGUAGEM/LÍNGUA PRESENTES NO ABC DO ALFABETIZADOR
}

\author{
Bruno Marini Bruneri \\ Universidade Federal de Mato Grosso do Sul - UFMS, Programa de Pós-graduação em Educação, Educação Social, \\ Corumbá, MS. Agência de fomento: CAPES. E-mail: marinib@gmail.com
}

\section{RESUMO}

O presente trabalho investigativo se propôs analisar a concepção de linguagem/língua presente no livro de formação do professor alfabetizador, intitulado 'ABC do Alfabetizador', material que compõe o Programa Alfa e Beto de Alfabetização, vendido por uma Organização Não Governamental denominada Instituto Alfa e Beto. Para tanto, optou-se para a realização desta investigação pela pesquisa de abordagem qualitativa cujas fontes de informação e os procedimentos de coleta são de cunho documental. Dessa maneira, para atender tais procedimentos, utilizou-se a técnica de pesquisa baseada na análise de conteúdo. Por fim, os resultados da pesquisa apontam a presença de uma concepção monológica de linguagem no material analisado. Ademais, idealiza um aprendiz linguisticamente perfeito, levando os docentes a recorrer às antigas práticas tradicionais de alfabetização, condenadas há décadas por pesquisadores e educadores da área.

Palavras-chave: linguagem/língua, Instituto Alfa e Beto, Concepção, manual do professor.

\section{ALFA E BETO LITERACY PROGRAM: CONCEPTS OF LANGUAGE/LANGUAGE PRESENTS IN THE ABC OF LITERACY}

\begin{abstract}
This investigative study aimed to analyze the conception of language this book in training of literacy teachers, entitled 'ABC of literacy', material that makes up the Programa Alfa and Beto de Alfabetização, sold by a Non Governmental Organization called Instituto Alfa e Beto. Therefore, it was decided to carry out this research for qualitative research whose sources of information and collection procedures are primarily on documentary evidence. Thus, to meet such procedures, we used the research technique based on content analysis. Finally, the survey results indicate the presence of a monological conception of language in the analyzed material. Moreover, it idealizes one linguistically perfect apprentice, leading teachers to resort to old traditional literacy practices, condemned for decades by researchers and educators in the area.
\end{abstract}

Keywords: Language, Alfa and Beto Institute, Concepts, teacher's manual. 


\section{INTRODUÇÃO}

Atualmente há uma crescente adoção e procura por materiais didáticos pautados em práticas alfabetizadoras embasadas teoricamente em ideários tradicionais, na esperança de uma solução para o mau desempenho dos resultados obtidos nas salas de alfabetização. Entretanto, esses materiais e métodos em um passado distante propiciaram sucesso em seus resultados, em uma escola pública que não tinha a configuração de uma escola pública como temos hoje.

O mais preocupante é que esses materiais não se esmeram em desenvolver a consciência crítica no educando e tampouco se baseiam em atividades reflexivas de compreensão da realidade, tendo em vista que, como dito, no seu ultrapassado decurso não foram suficientes para alfabetizar as massas que ocupavam os bancos escolares, tendo como consequência a exclusão de grande parte de seu contingente por meio de reprovas e evasão.

Entretanto, o que vem alimentando a busca por uma metodologia alfabetizadora que remediasse a agravante situação apresentada é a forte acusação dos defensores do método fônico que imputam o construtivismo pelo fracasso nas práticas alfabetizadoras atuais por meio de novas teorias, pesquisas e materiais didáticos que, ao buscarem bases nas ciências da linguagem reformularam o método fônico (ADAMS et al. 2006; CAPOVILA; CAPOVILA, 2004a; 2004b; MORAIS, 1996) e ganharam grande número de adeptos, repercussão midiática, atraíram os olhares dos professores e consequentemente de um grande mercado editorial.

Dentre esses simpatizantes, desde os anos 2000, a organização não governamental "Instituto Alfa e Beto" (doravante IAB) vem desenvolvendo materiais e programas de ensino pautados na abordagem fônica para a alfabetização sendo que seus produtos tiveram ampla repercussão em mais de uma dezena de redes estaduais de ensino, centenas de municípios brasileiros, bem como a entrada em países estrangeiros.

Sendo assim, partindo de pressupostos teóricos que concernem alfabetização, pautados na ciência Linguística, na Psicolinguística, bem como nos estudos sobre Educação, adotou-se como o objetivo deste trabalho analisar as concepções de linguagem/língua presentes no "ABC do Alfabetizador", livro de formação do professor alfabetizador, do Programa Alfa e Beto de Alfabetização, produzido pelo IAB.

\section{METODOLOGIA}

Quanto aos aspectos metodológicos da pesquisa, com a finalidade de examinar a proposta de linguagem/língua trazida pelo material didático pelo $I A B$, optou-se para a realização desta investigação pela pesquisa de abordagem qualitativa cujas fontes de informação e os 
procedimentos de coleta são de cunho documental. Dessa maneira, para atender tais procedimentos, utilizou-se a técnica de pesquisa baseada na análise de conteúdo.

Para a construção da análise documental, inicialmente, foi realizada uma leitura flutuante do documento para conhecimento, conexão entre o texto e o quadro teórico da pesquisa e a reflexão do pesquisador frente ao conteúdo encontrado. O segundo passo constitui-se pela organização e delimitação do corpus de estudo, a fim de delimitar os perímetros da pesquisa, que posteriormente serviram de material para elaboração do roteiro de análise. Feito isso, selecionouse as categorias de análise do documento que propiciaram a formatação do texto da pesquisa.

Escrito por João Batista Araujo e Oliveira, o 'ABC do Alfabetizador' tem formato grande (21 $x 28 \mathrm{~cm}$ ) e duas orelhas em branco. A capa tem fundo da cor marrom estampado com letras da mesma cor em tom de marca d'água, no centro o título do livro, no cabeçalho o nome do autor e no rodapé a logomarca colorida do Instituto Alfa e Beto, seguida do slogan da editora "Aprender a ler. Ler para aprender.", no canto inferior direito uma tarja branca escrita em preto o número da edição do livro.

O exemplar selecionado para esta análise encontra-se em sua 8a edição, datada no ano de 2008 e conta com a apresentação da 2a edição, de janeiro de 2004. No material não está explicitado o número de exemplares impressos por edição e conta com 517 páginas.

Apesar de o livro ser uma obra teórica, de formação de professores, ele apresenta um caráter bastante didático, escrita em linguagem acessível, contendo sínteses, quadros e gráficos. Feito a contextualização do corpus, segue análise do documento segmentada por categorias previamente estabelecidas.

\section{RESULTADOS/DISCUSSÃO}

O movimento de ensinar a ler e a escrever teria como objeto de ensino, preliminarmente, a manipulação (em seu uso e forma) da língua, no caso do Brasil, a língua portuguesa, por se tratar da língua oficialmente adotada pelo Estado.

Entretanto, ao ir à escola, a criança já sabe português, tendo em vista que ela ouve e fala a língua dominando aspectos morfossintáticos e semânticos capazes de compreender e de se fazer compreender durante o processo de interação verbal. Dentro dessa perspectiva, nas palavras de Cagliari (2009, p. 24), o "objetivo mais geral do ensino da língua portuguesa para todos os anos da escola é mostrar como funciona a linguagem humana [...]".

Segundo Koch (1995, p. 9), no decurso histórico a linguagem humana passou por três principais concepções: 
A mais antiga destas concepções é, sem dúvida, a primeira, embora continue tendo seus defensores na atualidade. Segundo ela, o homem representa para si o mundo através da linguagem e, assim sendo, a função da língua é representar (= refletir) seu pensamento e seu conhecimento de mundo. A segunda concepção considera a língua como um código através do qual o emissor comunica a um receptor determinadas mensagens. A principal função da linguagem é, nesse caso, a transmissão de informações. A terceira concepção, finalmente, é aquela que encara a linguagem como atividade, como forma de ação, ação interindividual finalisticamente orientada, como lugar de interação que possibilita aos membros de uma sociedade a prática dos mais diversos tipos de atos (Ibid).

Dentro dessa terceira concepção, que não nega as duas primeiras, mas as incorpora e amplia, entende que é através da linguagem "que o indivíduo, ao fazer uso da língua, não apenas exterioriza seu pensamento, não somente transmite informações; na verdade, mais do que isso, realiza ações, age, atua, orientado por determinada finalidade, sobre o outro" (CURADO, 2004, p. 19).

Assim, por intermédio da linguagem que o ser humano se expressa, comunica e principalmente medeia as relações em seu meio e consigo mesmo, que constrói o processo de saber por meio de novas construções relacionadas com anteriores, bem como produz os sentidos da comunicação nos processos de enunciação, sejam orais ou escritos.

Na trajetória histórica do ensino da leitura e escrita no mundo ocidental, foram criadas e discutidas as diferentes metodologias de ensino das primeiras letras baseadas nessas diferentes concepções de linguagem, bem como, na utilização da língua e da linguagem escrita a partir de surgentes necessidades do ler e escrever ao longo da trajetória histórica da sociedade ocidental (BRASLAVSKY, 1988).

Diante do exposto, o entendimento desses conceitos torna-se fundamental, logo,

[...] a maneira como o professor concebe a linguagem e a língua, pois o modo como se concebe a natureza fundamental da língua altera em muito o como se estrutura o trabalho com a língua em termos de ensino. A concepção de linguagem é tão importante quanto à postura que se tem relativamente à educação (Travaglia, 2000, p. 21).

Dentro dessa perspectiva, buscou-se o conceito de linguagem/língua explicito no 'ABC do Alfabetizador' e não se encontrou referência direta aos termos, tão pouco a localização histórica da criação do método fônico na tentativa de se traçar uma relação entre a necessidade de criação do método e a concepção de linguagem no dado momento histórico. 
Entretanto, o documento apresenta referência direta ao trabalho pedagógico relacionado a adequações da criança à "linguagem da escola" e outros indícios, como conceitos implícitos, que através da análise, levaram a compreensão desta categoria. Desse modo, se pensou na pertinência de apresentar primeiramente os indícios implícitos do conceito linguagem/língua ao compor uma linha coerente na tessitura textual. Assim, partiu-se do implícito para o explícito até chegar à compreensão dos pressupostos linguísticos que respaldam a metodologia alfabetizadora analisada.

Preliminarmente, não se torna difícil de entender os fundamentos linguísticos que alicerçam o método proposto por Oliveira (2008), logo, alguns elementos do texto evidenciam a assertiva, tais como: a conceituação limitada do alfabeto representativo de um código de transcrição da fala, entendido como um sistema fechado e arbitrário; a ênfase nas atividades mecânicas de decodificação e codificação; além das práticas de caligrafia, cópia, ditado, soletração e treino da leitura que redundam o método.

Todos esses elementos organizados de forma estruturada apontam para uma concepção de linguagem restrita às normas e formas da língua, como um sistema exato e fechado, cabendo à criança a sua mera assimilação e posterior reprodução. Dessa forma, considera-se que o centro organizador da linguagem situa-se no sistema linguístico, ou seja, no sistema das formas fonéticas, gramaticais e lexicais da língua (BAGATIN, 2012, p. 86)

Seguindo essa perspectiva, a língua estaria restrita as estruturas e normas, inflexíveis às variações resultantes das relações entre os sujeitos. Ao sistema linguístico caberia à subordinação do imperativo das regras, impassível de determinações ideológicas, artísticas ou de qualquer outra natureza relativa ao uso dos sujeitos falantes dela.

A esses indivíduos caberia apenas a obrigação de incorporar e imitar as estruturas linguísticas igualmente como elas são, deixando de lado qualquer possibilidade do caráter analítico desse sistema, de modo que o parâmetro válido seria o certo ou o errado, ou seja, o condizente com a norma ou o dissonante dela (BAGATIN, 2012).

Toda essa reflexão traz a possibilidade de se comparar o conceito linguagem/língua presente no ' $A B C$ ' aos dois conceitos primeiros inscritos na história dos estudos sobre a linguagem, especialmente ao primeiro. Vale lembrar que a história da alfabetização marca a criação do método fônico no século XVI, pelo gramático alemão Valentin Ickelsamer, cujo entendimento do conceito de linguagem circulante na época era de 'espelho' do pensamento ou 'representação' de seu entendimento do mundo. Como visto, a essência do método de Ickelsamer 
não foi modificada quando recebeu novas técnicas, ou apenas um novo nome, ao se transmutar em método metafônico criado por João Batista A. Oliveira (2008).

Ampliando a discussão, dentro dessa perspectiva, nas palavras de Curado (2004, p.19)

[...] Não se expressaria bem o indivíduo que não pensasse, porquanto a expressão construir-se-ia no interior da mente, a instância de produção, secundarizando-se a língua, útil apenas por exteriorizar, traduzir o pensamento. A eficiência comunicativa dependeria da capacidade de o indivíduo organizar de maneira lógica seu pensamento; para tal organização, haveria regras disciplinando-o e, como consequência, a própria linguagem. Daí, a valorização das normas gramaticais do falar e do escrever "bem". Diante de tal perspectiva, a enunciação (a ação de enunciar) põe-se como ato monológico, individual, prescindindo-se do outro e das circunstâncias, da situação social em que a enunciação ocorre. Os estudos linguísticos aí desenvolvidos encontram-se sob a denominação de gramática tradicional ou normativa (Ibid, grifos do autor).

Esses conceitos implícitos no documento e exemplificados nas falas de Bagatin (2012) e Curado (2004) podem ser evidenciados no momento em que explicitamente no material se elege a linguagem da escola, ou seja, a linguagem padrão, da norma dita culta, como concepção de linguagem e língua entendidas como corretas, visualizada no seguinte trecho introdutório ao subitem do Capítulo 2, "A linguagem da escola", nas palavras do autor:

Além de desenvolver o vocabulário próprio e adequado para conversar sobre a língua e a capacidade de brincar com a linguagem, um processo de alfabetização bem-sucedido requer que a criança que não sabe aprenda a lidar com outros três conjuntos de competências: a língua falada padrão, as palavras que expressam conceitos básicos e os comandos da escola (OLIVEIRA, 2008, p. 74).

Essas competências, que levariam a formação de um falante perfeito, no caso o alfabetizando, dominar os padrões da língua, consistiria em seguir os modelos e obedecer aos comandos da escola, que, segundo o autor, se utiliza de um vocabulário próprio e de conceitos que a criança não domina, pois sua linguagem, ou seja, a variante dialetal familiar, em suas palavras "podem soar como uma língua estrangeira para os alunos que nunca freqüentaram uma escola" (OLIVEIRA, 2008, p. 77).

Assim, a arbitrariedade do sistema linguístico tenta afunilar os espaços da justificação ideológica por parte dos sujeitos. A própria mudança da língua ao longo da história é entendida como um erro, como algo que saiu do script, que burlou as normas estabelecidas. Não há espaço para a criatividade e muito menos para a antítese. O sujeito deve somente respeitar as regras do sistema linguístico (BAGATIN, 2012, p. 87). 
Tendo em vista que no 'ABC' a linguagem se apoia na perspectiva do falante perfeito, dominante da norma padrão, nessa direção, retomando a ideia de Travaglia (2000), a adoção da concepção de linguagem, implicaria em posicionamentos de posturas educacionais, tais como, a anulação da participação do sujeito em seu próprio processo de aprendizagem, de uma exigente educação sistematizada, padronizada, sem reflexão, como sugere o desenvolvimento da terceira competência do aprendizado dos "comandos da escola":

Comando exige ação, exige resposta. Ensinar comandos não significa apenas ensinar o significado das palavras: levante-se, segure corretamente o lápis, sublinhe as frases com ponto de interrogação. Ensinar comandos significa quais comandos seguir cegamente e quais são passíveis de discussão ou de aprovação coletiva. Ao aprender a conviver com comandos o aluno está aprendendo valores fundamentais para a vida social: ordenar, organizar, coordenar, mandar, obedecer, em síntese, está aprendendo não apenas as palavras, mas o poder das palavras (OLIVEIRA, 2008, p. 77).

Em um método que compreende a linguagem escrita como um código a ser decifrado, representativo de sons da fala, não poderia exigir uma postura crítica de seu aluno, pois, nessa perspectiva, necessariamente todos os falantes deveriam reproduzir na leitura igualmente os sons representados pelas letras.

\section{CONCLUSÃO}

O presente trabalho investigativo se propôs analisar a concepção de linguagem/língua presente no livro de formação do professor alfabetizador, intitulado 'ABC do Alfabetizador', material que compõe o Programa Alfa e Beto de Alfabetização, vendido por uma Organização Não Governamental denominada Instituto Alfa e Beto.

A escolha do tema partiu da preocupação da veracidade dos baixos índices de letramento dos alunos das escolas brasileiras decorridos de um processo de alfabetização insuficiente para atender as necessidades que a sociedade contemporânea grafocêntrica exige na atualidade, bem como pela grande abrangência que esse Programa de Alfabetização possui nos processos educativos, influenciando diretamente as práticas pedagógicas propostas para o ciclo de alfabetização que vem sendo cada vez mais implantadas por vários municípios, estados e países.

Este trabalho comunga da ideia de que a linguagem formal, através da língua padrão, deve ser empregada na escola e, seu uso ensinado aos seus educandos, entretanto, a postura metodológica empregada nas salas de alfabetização deve privilegiar essa concepção como uma das inúmeras possibilidades de interação verbal em diferentes esferas comunicativas, como forma de relação social, atuando e agindo sobre o outro, assim como apontou Curado (2004). 
Deste modo, cabe à escola a grande responsabilidade de mostrar à criança sem constrangê-la, ao contrário, valorizando sua fala, que há um outro modo de se falar que é a língua da escola, dos livros, das revistas, da televisão, do rádio, enfatizando a necessidade de aprender este outro jeito de falar. A partir do momento que a escola apresenta esta segunda forma de expressão verbal e mostra que as duas formas - padrão e não padrão - podem ser usadas dependendo da situação, formal ou informal, estará não só aceitando e respeitando a vez e a voz do aluno, mas dando subsídios para que possa desenvolver sua capacidade de expressão, e oferecendo instrumentos para que não seja discriminado em função de sua fala, e ainda, por meio do domínio pleno da oralidade domine também a língua escrita [...] (MENDONÇA, 2004, p. 20, grifos da autora)

Dentro dessa perspectiva, o trabalho com a linguagem/língua se centraria num processo reflexivo elevando o trabalho pedagógico ao objetivo do entendimento do funcionamento da linguagem humana, como sugerido por Cagliari (2009). O pensamento contrário, como o adotado pelo ' $A B C$ ', limitaria o ensino/aprendizagem, reduzindo os objetivos da alfabetização aos caprichos dos passos do método.

Por fim, a concepção monológica de linguagem adotada pelo autor do material, centrada no sujeito linguisticamente perfeito, conduzirá todo o caminho percorrido pelo professor e aluno durante o processo de ensino/aprendizagem das primeiras letras, recorrendo às antigas práticas tradicionais de alfabetização, condenadas há décadas por pesquisadores e educadores da área.

\section{REFERÊNCIAS}

ADAMS, M. J.et al.. Consciência fonológica em crianças pequenas. Porto Alegre: Artmed, 2006.

BAGATIN, T. Alfabetização em foco: uma análise do método fônico e sua ascensão no cenário nacional. 2012.132 f. Dissertação (Mestrado em Educação) - Setor de Educação, Universidade Federal do Paraná, Curitiba. 2012.

BRASLAVSKY, B. P. O método: panaceia, negação ou pedagogia? Trad. Adriana Fridzman. Cadernos de Pesquisa. São Paulo, n. 66, agosto 1988.

CAMACHO, R. G. Norma culta e variedades linguísticas. IN: CECCANTINI, J.L.C.T.; PEREIRA, R. F.; ZANCHETA JUNIOR, J. (org.) Pedagogia Cidadã - Cadernos de formação: Língua Portuguesa, São Paulo: UNESP, Pró-Reitoria de Graduação, 2004. p. 47-59.

CAGLIARI, L. C. Alfabetizando sem o BÁ-BE-BI-BÓ-BU. São Paulo: Scipione, 1998.

CAPOVILLA, A. G. S.; CAPOVILLA, F. C. Alfabetização: método fônico. São Paulo: Memnon, 2004(a).

CAPOVILLA, A. G. S.; CAPOVILLA, F. C. Problemas de leitura e escrita: como identificar, prevenir e remediar numa abordagem fônica. 4 ed. São Paulo: Memnon, 2004(b). 
CURADO, O. H. F. Linguagem e dialogismo. IN: CECCANTINI, J.L.C.T.; PEREIRA, R. F.; ZANCHETA JUNIOR, J. (org.) Pedagogia Cidadã - Cadernos de formação: Língua Portuguesa, São Paulo: UNESP, Pró-Reitoria de Graduação, 2004. p. 19-26.

KOCH, I. V. A inter-relação pela linguagem. 2. ed. São Paulo: Contexto, 1995.

MENDONÇA, O. S. A norma culta e a oralidade em sala de aula. IN: COELHO, S. M.; MENDONÇA, O. S. (org.) Pedagogia Cidadã - Cadernos de formação: Alfabetização. São Paulo: UNESP, Pró-Reitoria de Graduação, 2004. p. 19-26.

MORAIS, J. A arte de ler. Trad. Álvaro Lorenciani. São Paulo: Editora UNESP, 1996.

OLIVEIRA, J. B. A e. ABC do Alfabetizador. Belo Horizonte: Instituto Alfa e Beto, 2008.

TRAVAGLIA, Luiz Carlos. Gramática e interação: uma proposta para o ensino de gramática no $1^{\circ} e$ $2^{\circ}$ graus. 5. ed. São Paulo: Cortez, 2000. 